\title{
Psychological and Linguistic Determinants of Educational Adjustment Among Thai Students Enrolled in First-Year Thai University English Language Courses
}

\author{
Yeo Hoon Kim \\ Prince of Songkla University, \\ Phuket, Thailand
}

\author{
Graham R. Davidson, Robert Ho \\ Assumption University, \\ Bangkok, Thailand
}

\begin{abstract}
Drawing on disparate research into factors influencing educational adjustment, this study examined the relative influence of English language proficiency, English language self-efficacy, foreign language classroom anxiety, psychological coping strategies, aspects of mental health, and educational motivation on the educational adjustment of Thai students enrolled in first-year Thai university English language courses. A total of 477 Thai-speaking students taking first-year introductory English courses in two faculties at a Thai university participated in this study, which involved completion of a questionnaire translated into Thai using a combination of back translation, committee deliberation, and field testing techniques. Hierarchical regression analysis showed that depression was the strongest predictor of educational adjustment, followed by motivation to develop occupational talents. Foreign language classroom anxiety, active psychological coping, and English language self-efficacy were also found to be strong predictors. English language proficiency as measured by TOEIC (Test of English for International Communication) was not found to be a reliable predictor of educational adjustment, arguably because of the overall bilingual nature of these students' first-year experience. Availability and use of additional psycho-educational and psychological counseling assistance may benefit NESB (non-English-speaking backgrounds) students who are required to study English by reducing foreign classroom language anxiety, increasing English language self-efficacy, increasing motivation to improve one's occupational talents, and reducing symptoms of depression.
\end{abstract}

Keywords: mental health, English proficiency, educational adjustment, first-year university, NESB (non-English-speaking backgrounds), Thailand

\section{Introduction}

The first-year university experience can be problematical for many students. History suggests that first-year university students have always faced more complex and demanding changes and challenges than they experienced in their high school years, many of which relate directly to their ability to come to terms with university courses, teachers, and library use (Eaele, 1936). It is the most vulnerable period for students in terms of probability of academic failure, dropping out of study, and increased social and emotional difficulties

Yeo Hoon Kim, M.S. (counseling psychology), lecturer, Faculty of International Studies, Prince of Songkla University. Graham R. Davidson, Ph.D., emeritus professor, Graduate School of Psychology, Assumption University.

Robert Ho, D. Phil., associate professor, Graduate School of Psychology, Assumption University. 
(McInnis, 2001). Entrance to university symbolizes a challenging transitional step in young people's lives. For many students, successful separation from parents and family and the establishment of emotional independence have a positive influence on educational adjustment (Lapsley, Rice, \& Shadid, 1989; Hoffman, 1984). How they adjust to and cope with the educational and extracurricular demands of university life, including new and different responsibilities and challenges, is a critical factor in their academic success (Gan, $\mathrm{Hu}$, \& Zhang, 2010).

\section{Factors Influencing Educational Adjustment}

English language proficiency. In universities where the medium of instruction is English, which has been the setting for much of the research into educational adjustment to university, academic and social adjustment of students from NESB (non-English-speaking backgrounds) may be influenced by their level of English language proficiency (Khawaja \& Dempsey, 2007). For example, Swagler and Ellis (2003) found that Taiwanese students in the United States identified English language proficiency as their major educational obstacle. Lower levels of English language proficiency affect not only students' academic progress, but also their experience of university life in general. Students with lower levels of English proficiency tend to have more school-related problems, such as attention and learning difficulties (Dowdy, diStefano, Dever, \& Chin, 2011), as well as limited desire to seek social interactions (Olivas \& Li, 2006).

Linguistic self-efficacy. In addition to language proficiency, psycho-educational and psychosocial factors play a role in educational adjustment. Firstly, educational self-efficacy is a reliable predictor of students' motivation and learning (Zimmerman, 2000). Self-efficacy is a closely related concept to self-concept; however, self-efficacy is a better indicator of level of students' belief in their ability and subsequently of their educational performance. Linguistic self-efficacy (one's belief in specific aspects of one's linguistic capability) contributes positively to language learning motivation. Developing a sense of linguistic self-efficacy early in language learning tends to benefit students' performance (Cotterall, 1999; Tremblay \& Gardner, 1995).

Foreign language anxiety. Anxiety is often correlated with second language learning, so that foreign language anxiety may limit students' effective acquisition of a second language (Horwitz, 1986, 2001; E. K. Horwitz, M. B. Horwitz, \& Cope, 1986). Gardner and Lambert (1959) regarded the motivational factor of foreign language anxiety as one of the top two factors (the other being linguistic aptitude) in second language learning. Less anxious learners tend to be more enthusiastic, engaged, and focused. They are interested in what they are doing and they try hard to overcome the challenges of second language acquisition (Garris, Ahlers, \& Driskell, 2002).

Psychological coping and educational motivation. Motivation and psychological coping are related processes, so that coping style may also influence educational motivation. Furthermore, problem-focused coping strategies may play a positive role in students' motivation and academic performance (Struthers, Perry, $\&$ Menec, 2000). Problem-focused, or active, psychological coping helps students to pay attention to specific goals and allows them to view the situation as more controllable; hence, active coping is likely to be positively related to psychological wellbeing and academic success. In contrast, students who engage in avoidant psychological coping tend to view the situation as less controllable and are less likely to achieve success or exhibit positive psychological wellbeing (Park \& Adler, 2003; Ben-Zur, 2009). Educational motivation on the other hand refers to students' beliefs about what is important in academic situations (Fadlelmula, 2010). The decade-long study of Krause, Hartley, James, and McInnis (2005) found that the highly motivated university 
students overall have better academic results. Kuh (2007) also found that motivation and average grades are positively related. Among $\mathrm{C}$ grade average students, $42 \%$ reported that they were highly motivated. This percentage increased as grades increased. About $70 \%$ of the B grade average students rated themselves as highly motivated, and $79 \%$ of the students who achieved an A grade rated themselves as highly motivated. Kuh (2007) concluded that highly motivated students tend to perform better academically than poorly motivated students. Moreover, the absence of motivation is associated with poor psychosocial adjustment to university life, high levels of perceived stress, and poor general wellbeing (Baker, 2004).

Mental health. Psychosocial factors, such as educational self-efficacy and psychological coping, and resultant academic performance also appear to be closely related to mental health. Students with low self-efficacy tend to focus on how difficult school life might be, doubt if they are able to manage their studies, and tend to exhibit more stress (Zajacova, Lynch, \& Espenshade, 2005). Problems with second language learning can be one of the stressors (Misra, Crist, \& Burant, 2003). Moreover, students with higher levels of general anxiety tend to assess the situation as threatening and unmanageable, which often leads to poor academic adjustment and failure (Cohen, Ben-Zur, \& Rosenfeld, 2008).

\section{Second Language Learning and First-Year University Adjustment}

Although there is a considerable amount of research into factors influencing students' adjustment to the first year of university as well as into learning in a second language, such as English, less research has been undertaken with NESB students who are required to adjust simultaneously to first-year university study and an English language classroom environment. Furthermore, the majority of research into foreign language learning has been conducted with NESB college and university students studying abroad in English language medium universities. However, the role that English language proficiency plays in students' adjustment to university is becoming increasingly relevant in higher education contexts where instruction traditionally has been in languages other than English, e.g., in many Thai universities where most future, new programs are likely to be "international" in nature, involving compulsory second language (mainly English) learning (Wiriyachitra, 2002). After enrolling in such programs, first-year Thai university students who have limited English proficiency are likely to be required to take non-credit remedial English courses before proceeding to compulsory for-credit English language courses, while other Thai students who have greater English proficiency are generally allowed to enroll in compulsory for-credit first-year English courses. Hence, students with greater English proficiency are more likely to progress at a faster rate through university. However, all Thai students enrolling in these new programs are confronted by the dual challenges of learning, and learning in English as a foreign language, as they embark on their university studies.

The current research, therefore, aimed to: (1) provide a more thorough understanding of the educational adjustment of Thai students who are going through a transitional period (first year) of adjusting to university where the English language medium of instruction is neither their first language nor the language of the broader community; and (2) examine the relationship between English language proficiency, English language self-efficacy, foreign language anxiety, psychological coping, mental health, educational motivation, and educational adjustment among these NESB Thai students. Based on the research findings from English language medium universities, it was hypothesized that better educational adjustment of Thai students enrolled in Thai university first-year English language courses will be associated with and predicted by greater English language proficiency, higher English language self-efficacy, lower foreign language 
anxiety, more use of active psychological coping, less reliance on avoidant psychological coping, fewer symptoms of depression, anxiety, and stress; and greater motivation to study and to prepare for a career. Equally importantly, the present research sought to clarify the relative contribution of these factors to educational adjustment so that local universities and, hopefully, overseas English language medium universities might assist first-year NESB students to adjust to university life by allowing resources to be channeled toward classroom-based, remedial, career and personal counseling, or other educational support services that are most needed.

\section{Method}

\section{Participants}

The participants were 477 Thai-speaking students from Prince of Songkla University, Phuket Campus, Thailand, enrolled in first-year introductory English courses in the first semester of 2011. Students whose first language was not Thai were excluded from the study. Prior to data analysis, seven participants' questionnaires were eliminated from the sample because they failed to complete all or a major part of one or more questionnaire components, leaving a final sample of 470 (364 females, 104 males, and 2 unspecified) for analysis. Participants were drawn from the Faculties of International Studies $(n=212)$ and Hospitality and Tourism ( $n=256 ; 2$ unspecified). The sample consisted of first-year $(n=295)$ and advanced (second- to fourthyear; $n=173 ; 2$ unspecified) students, the latter being students who were repeating non-credit remedial or for-credit first-year English classes.

\section{Materials}

The self-report questionnaire consisted of six sections. Section 1 sought information on students' gender, age, faculty in which they were enrolled, year of study, previous university experience, residential arrangements, and TOEIC (Test of English for International Communication) score, which was used as a measure of English language proficiency (Woodford, 1982). Princeton University Educational Testing Service reported that the test-retest reliability of TOEIC was 0.96 , based on its administration to 2,710 test-takers in Japan in 1979 (Chapman, 2006). TOEIC scores correlated $r=0.83$ with other measures of ESL (English as a second language) proficiency (Wilson, 2001).

Section 2 consisted of four items written by the researchers to measure English language self-efficacy. These items were written to gauge students' perceived ability separately to understand, speak, read, and write English. Each item was to be rated on a 5-point Likert scale ranging from 1 ("Not at all") to 5 ("Excellent"), e.g., "How well do you think you understand when someone speaks English?" Reliability analysis indicated that this overall measure of English language self-efficacy was internally consistent with a Cronbach's alpha of 0.78 .

Section 3 consisted of the 33-item Foreign Language Classroom Anxiety Scale (Horwitz et al., 1986) used to assess students' foreign language anxiety. Students rated their level of foreign language anxiety from 1 ("Strongly agree") to 5 ("Strongly disagree"). Seven items were reverse scored, so that a low score on each item reflected heightened foreign language anxiety. Reliability analysis resulted in the removal of one item, and the final scale returned a Cronbach's alpha of 0.90 .

Section 4 consisted of the 16-item Brief COPE (Welbourne, Eggerth, Hartley, Andrew, \& Sanchez, 2007) which was developed to measure active, avoidant, and emotional psychological coping. Each item was rated 
from 1 ("I have not been doing this at all") to 5 ("I have been doing this a lot"), with high scores indicating a higher tendency to employ that coping strategy. Internal reliabilities $(\alpha)$ for active, avoidant, and emotional coping in the present study were $0.77,0.74$, and 0.80 respectively.

Section 5 consisted of the Thai version of the DASS-21 (Depression, Anxiety, and Stress Scale-21) (Henry \& Crawford, 2005; National Centre in HIV Epidemiology and Clinical Research, 2007). Each item was rated on a 4-point scale ranging from 0 ("Did not apply to me at all") to 3 ("Applied to me very much, or most of the time"), with high scores indicating high symptoms of depression, anxiety, or stress. Internal reliabilities $(\alpha)$ for stress, anxiety, and depression in the present study were $0.84,0.78$, and 0.79 respectively.

Section 6 consisted of two items written to assess educational motivation. The first item ("I find it difficult to get myself motivated to study"), which was adapted from the First-Year Experience Questionnaire developed by McInnis and James (1995), measured students' motivation to study. The second item ("I am motivated to develop my talents for the occupation I want to pursue") was adapted from Krause, Hartley, James, and McInnis (2005). Both items were rated on a 5-point Likert scale ranging from 1 ("Strongly agree") to 5 ("Strongly disagree"), with high scores indicating low educational motivation and high career motivation respectively. Internal reliability $(\alpha=0.40)$ was low and therefore these items were entered separately into the regression analysis.

Section 7 consisted of the 37-item First-Year Experience Questionnaire (McInnis \& James, 1995), which was developed to measure educational adjustment to university study in the form of academic adjustment, personal and emotional adjustment, and personal engagement. Each item was rated on a 5-point Likert scale ranging from 1 ("Strongly disagree") to 5 ("Strongly agree"). Of the 37 items, 10 were reverse-scored so that a high score overall indicated greater educational adjustment. Internal reliability $(\alpha)$ for the full scale score in the present study was 0.86 .

\section{Procedure}

The original questionnaire was in English except for the Thai version of the DASS-21 (National Centre in HIV Epidemiology and Clinical Research, 2007). In order to maximize NESB Thai participants' comprehension, the English sections of the questionnaire were translated from English to Thai. A combination of the back-translation and committee approaches was used in the translation. After the translation had been completed, a field test was conducted separately with two bilinguals to ensure that translated items and instructions were comprehensible (Brislin, 1970; Cha, Kim, \& Erlen, 2007).

Students from the Faculties of International Studies and of Hospitality and Tourism enrolled in first-year English courses were visited by the first researcher in their classrooms and invited to fill in the questionnaire. An information sheet was provided and the research procedure was explained verbally, including the identity of the first researcher, general purpose of the research, voluntary nature of students' participation, and the anonymity of their responses. Students deposited their completed questionnaires in a box placed at the classroom door as a further assurance of anonymity.

\section{Research Design}

The study employed hierarchical regression analysis to investigate the predictive relationships between English language proficiency, English language self-efficacy, foreign language classroom anxiety, active coping, avoidant coping, emotional coping, depression, anxiety, stress, and educational motivation (study and career) and the criterion variable of educational adjustment. The hierarchical nature of the analysis entailed the 
entry of the variables in blocks into the prediction equation with the order of entry of these blocks being determined by the variables' theoretical and empirical importance in contributing to the explanatory power of the overall equation. The chosen order was based on previous research primarily into the relationships between attitudes about language learning, linguistic self-efficacy, foreign language anxiety, motivation to learn a second language, and second language proficiency (Gardner \& Lysynchuk, 1990; Lalonde \& Gardner, 1984; Liu, Benner, Lau, \& Kim, 2009; Rueda \& Chen, 2005). Thus, block 1 containing the general psychological variables of depression, anxiety, stress and coping was entered first into the prediction equation, followed by block 2 containing the educational motivation variables of study and career, followed by block 3 containing the language-related psychological variables of English language self-efficacy and foreign language classroom anxiety, and followed finally by block 4 containing the variable of prior English language proficiency (as measured by students' TOEIC scores). In this way, the hierarchical nature of entry allowed the analysis first to remove the variance associated with the distal measures of mental health and coping, before removing the variance associated with psycho-educational and language-related psychological variables, and finally accounting for the remaining variance that could be attributed to the proximal variable of prior English language proficiency.

\section{Results}

Table 1 presents the $M$ (means) and $S D$ (standard deviations) for the measurement variables under investigation. The number of participants for whom a TOEIC score was available was 444, while scores on the other measurement variables were available for all 470 participants. The mean TOEIC score of 338.18 fell below the set criteria for entry into for-credit English courses in both the Faculty of International Studies (for which a TOEIC score of above 400 was required) and the Faculty of Hospitality and Tourism (for which a TOEIC score of above 450 was required). Mean scores for the three DASS-21 variables indicated that depression levels in the sample on average were normal to mild, stress levels on average were mild, and anxiety levels on average were moderate. Nevertheless, further frequency analyses of DASS-21 scores using clinical cut off scores for the original English version of the DASS (S. H. Lovibond \& P. F. Lovibond, 1995) suggested that $15 \%$ of the sample reported severe symptoms of stress, $26.2 \%$ reported severe symptoms of anxiety, and $8 \%$ reported severe symptoms of depression.

Hierarchical regression analysis was used to determine the predictors of educational adjustment. Results of the analysis are presented in Tables 2 and 3.

Table 2 shows that entry of the block 1 of variables (Model 1: stress, anxiety, depression, active coping, avoidant coping, and emotional coping) accounted for $25 \%$ of the variance in the criterion variable of educational adjustment $\left(R^{2}=0.25\right)$ which is statistically significant $(p<0.001)$. Entry of the block 2 of variables (Model 2: educational motivation—study, educational motivation—occupation talents) accounted for an additional $3 \%$ of the variance in educational adjustment $\left(R^{2}\right.$-change $\left.=0.03\right)$ which is statistically significant $(p<0.001)$. Entry of the block 3 of variables (Model 3: foreign language classroom anxiety, English language self-efficacy) accounted for a further $3 \%$ of the variance in educational adjustment $\left(R^{2}\right.$-change $\left.=0.03\right)$ which is statistically significant $(p<0.001$ ). Entry of the block 4 of variables (Model 4 : English language proficiency as measured by the students' TOEIC scores) accounted for an additional $1 \%$ of the variance in educational adjustment $\left(R^{2}\right.$-change $\left.=0.01\right)$ which is not statistically significant $(p>0.05)$. 
Table 1

$M$ and SD for: TOEIC; Educational Motivation-Study, and Occupational Talents; DASS-21 Stress, Anxiety, and Depression; Foreign Language Classroom Anxiety; Active, Avoidant, and Emotional Coping; English Language Self-efficacy; and Educational Adjustment

\begin{tabular}{llrr}
\hline Variable & $N$ & $M$ & \multicolumn{1}{l}{$S D$} \\
\hline TOEIC & 444 & 338.18 & 77.91 \\
Educational motivation-Study & 470 & 3.28 & 0.93 \\
Educational motivation-Occ. talents & 470 & 4.12 & 0.65 \\
Educational adjustment total & 470 & 128.52 & 15.16 \\
DASS-21 stress & 470 & 7.73 & 4.88 \\
DASS-21 anxiety & 470 & 5.76 & 4.20 \\
DASS-21 depression & 470 & 5.08 & 3.98 \\
Foreign language classroom anxiety & 470 & 94.11 & 15.65 \\
Active coping & 470 & 19.10 & 3.04 \\
Avoidant coping & 470 & 19.49 & 3.11 \\
Emotional coping & 470 & 6.58 & 2.26 \\
English language self-efficacy & 470 & 10.54 & 2.16 \\
\hline
\end{tabular}

Table 2

Hierarchical Multiple Regression Analysis Model Summary

\begin{tabular}{llllll}
\hline \multirow{2}{*}{ Model } & \multicolumn{5}{c}{ Change statistics } \\
\cline { 2 - 5 } & $R^{2}$-change & $F$-change & $d f 1$ & $d f 2$ & Sig. $F$-change \\
\hline 1 & 0.25 & 23.69 & 6 & 437 & 0.000 \\
3 & 0.03 & 9.23 & 2 & 435 & 0.000 \\
4 & 0.03 & 9.53 & 2 & 433 & 0.000 \\
\hline
\end{tabular}

Table 3

Hierarchical Multiple Regression Coefficients

\begin{tabular}{lcccc}
\hline & \multicolumn{3}{c}{ Unstandardized coefficient } & \multicolumn{2}{c}{ Standardized coefficient } \\
\cline { 2 - 3 } \cline { 5 - 6 } & $B$ & Std. error & Beta $(\beta)$ & $t$ \\
\hline Active coping & 0.71 & 0.25 & 0.14 & $2.79^{* *}$ \\
Avoidant coping & 0.39 & 0.25 & 0.08 & $1.60^{\wedge}$ \\
Emotional coping & -0.45 & 0.28 & -0.07 & $-1.58^{\wedge}$ \\
DASS-21 stress & -0.15 & 0.22 & -0.05 & $-0.68^{\wedge}$ \\
DASS-21 anxiety & 0.54 & 0.24 & 0.15 & $2.24^{*}$ \\
DASS-21 depression & -1.17 & 0.25 & -0.31 & $-4.61^{* * *}$ \\
Educational motivation-Study & 0.23 & 0.71 & 0.01 & $0.32^{\wedge}$ \\
Educational motivation-Occ. talents & 3.51 & 0.97 & 0.15 & $3.62^{* * *}$ \\
Foreign language classroom anxiety & 0.15 & 0.05 & 0.15 & $3.08^{* *}$ \\
English language self-efficacy & 0.82 & 0.30 & 0.12 & $2.71^{* *}$ \\
TOEIC & -0.02 & 0.01 & -0.08 & $-1.93^{\wedge}$ \\
\hline
\end{tabular}

Notes. ${ }^{* * *} p<0.001 ;{ }^{* *} p<0.01 ;{ }^{*} p<0.05 ;{ }^{\wedge} \mathrm{ns}$.

Table 3 presents the standardized regression coefficients for the 11 predictor variables. The results showed that active psychological coping $(\beta=0.14, p<0.01)$, anxiety $(\beta=0.15, p<0.05)$, depression $(\beta=-0.31, p<$ $0.001)$, motivation to develop occupational talents $(\beta=0.15, p<0.001)$, foreign language classroom anxiety $(\beta$ $=0.15, p<0.01)$, and English language self-efficacy $(\beta=0.12, p<0.01)$ significantly predicted educational adjustment. Thus, students who engaged in more active coping, who were more anxious but less depressed, who were more motivated to develop occupational talents, who had lower foreign language anxiety, and who 
had higher English language self-efficacy had higher levels of educational adjustment. Depression was the strongest predictor followed by motivation to develop occupational talents. Foreign language classroom anxiety, active psychological coping, and English language self-efficacy were also strong predictors of educational adjustment. English language proficiency $(\beta=-0.08)$ as measured by TOEIC was not a significant predictor of educational adjustment.

\section{Discussion}

The present study sought to investigate the influence of English language proficiency, English language self-efficacy, foreign language classroom anxiety, psychological coping, aspects of mental health in the form of stress, anxiety and depression, and educational motivation on the educational adjustment of Thai NESB university students enrolled in compulsory introductory (first-year) English language programs in a Thai university context. In doing so, it aimed to provide a better and more detailed understanding of factors influencing educational adjustment of these NESB students. The focus on the criterion variable of educational adjustment is important because such adjustment is known to predict educational success and students' attrition (Krause et al., 2005).

Contrary to expectation, students' TOEIC scores did not significantly predict educational adjustment. This finding does not support the past research findings (e.g., Khawaja \& Dempsey, 2007) that low English language proficiency limits students' academic success and social interactions. However, English self-efficacy was found to be a strong predictor of educational adjustment. This finding is not inimical to the findings of Zajacova, Lynch, and Espenshade (2005) that self-efficacy positively influenced first-year students' grades and credits. Foreign language classroom anxiety was also found to be a strong predictor of educational adjustment. This finding is consistent with Woodrow's (2006) study of second language anxiety among English language learners, which showed that NESB students may experience in-class and out-of-class anxiety about using English. Brown (2008) studied language anxiety of international postgraduate students in British universities. At the time of her research, IELTS (International English Language Testing System) 6 (on a 9-band scale) was the minimum entry qualification for most British universities. She found, in contrast partly with our current findings that: (1) Many international NESB students experienced anxiety about communicating and studying in English; and (2) The level of English proficiency with which many students entered university inhibited their successful academic and socio-cultural adjustment. In addition to feeling anxious, the majority of the students also felt shame and inferiority. Our results offer support for the findings of Swagler and Ellis (2003) whose research suggested that: (1) self-confidence in using English and not English language proficiency "per se" was the major factor influencing students' educational adjustment; and (2) adjustment to living overseas was better predicted by students' perceived confidence in using English than by their actual language fluency.

In order to understand the reason why English language proficiency was not a significant predictor of educational adjustment in the present study, its overall importance for these students needs to be examined. For overseas NESB students studying in English-speaking countries, increased English language proficiency and self-efficacy are important to their management of academic and everyday life. Swagler and Ellis (2003) found Taiwanese students in the United States reported that their limited level of confidence in speaking English language was a major educational obstacle. Students also reported that having a sense of limited proficiency in English was the most significant and problematic adjustment factor they encountered, especially when English proficiency was directly relevant for learning. In a similar fashion, among 134 overseas students at the 
University of Ryukyus, 74 (55.2\%) reported inadequate language ability as the most significant stressor limiting their achievement of academic goals (Randall, Naka, Yamamoto, Nakamoto, Arakaki, \& Ogura, 1998). Limited English language proficiency tends to impede overseas NESB students' desire to seek social interactions. It creates in them counterproductive feelings about their ability to adjust successfully to new learning environments and may adversely influence their self-concept and self-efficacy (Olivas \& Li, 2006).

At the Thai university where our research was conducted, despite the finding that students' mean TOEIC scores fell below the for-credit English language cut-offs for both faculties, level of English language proficiency does not play a dominant role in the students' academic or everyday life for a number of reasons. Not all classes are taught in English; and the majority of the extracurricular activities are conducted in Thai, which is the first language of the great majority of the students enrolled at the university. Academic and personal counseling are also offered in Thai. Therefore, it is possible, and relatively easy, for these students to negotiate campus life and make progress with their studies without being highly proficient in English.

The results showed that active psychological coping strongly predicted educational adjustment. Active coping is effective in problem-solving and meeting everyday challenges (Ben-Zur, 2009). Avoidant psychological coping did not significantly predict educational adjustment. This finding is somewhat discrepant with the notion that avoidant coping is the least productive coping style, and therefore, might have been associated with lower educational adjustment (Ben-Zur, 2009). After accounting for the variance associated with other predictors of educational adjustment, emotional psychological coping was not found to be a significant predictor of educational adjustment, supporting previous findings that active coping and not emotional coping may have more influence on students' academic performance (Struthers et al., 2000).

The results showed that depression was the strongest predictor of educational adjustment, followed by motivation to develop occupational talents. This finding supported previous research findings that more depressed students are less well-adjusted academically (Hysenbegasi, Hass, \& Rowland, 2005). Anxiety was also a significant predictor of educational adjustment. However, interpretation of this finding is not clear cut. The hierarchical regression analysis showed that anxiety positively predicted adjustment, i.e., increased anxiety is associated with better educational adjustment. It seems, therefore, that a certain degree of anxiety is necessary if students are to master successfully the challenges of adjusting to university and learning a second language. However, excessive anxiety may actually inhibit educational adjustment, so that highly anxious students are likely to adjust less well to study and may even fail to thrive academically (Cohen, Ben-Zur, \& Rosenfeld, 2008). Thus, the relationship between anxiety and adjustment might not be linear but might instead be curvilinear, so that both very low and very high anxiety may be impediments to educational adjustment. Furthermore, not adjusting well to new educational challenges may have a reciprocal influence on state anxiety. Stress did not significantly predict educational adjustment; thus, low levels of stress were not positively related to better levels of adjustment. The results appear to be counterintuitive to those of Gan, Hu, and Zhang (2010), and Misra and Castillo (2004) who found that the first year of university was a stressful time due to the new educational and social challenges which students encounter.

While motivation to study did not significantly predict educational adjustment, motivation to develop vocational talents, along with depression, was one of the two strongest predictors of educational adjustment. This finding is consistent with the emphasis given by Krause et al. (2005, p. v) to the importance placed by first-year Australian students on "prepar(ing) for a career" and "achiev(ing) career goals" as motives for undertaking university studies. 
Based on group difference analyses of the same data set, Kim, Davidson, and Ho (2011) reported that males of Faculty of Hospitality and Tourism students, and advanced year students reported higher English language self-efficacy and less foreign language classroom anxiety than females of Faculty of International Studies students, and first-year students respectively. Faculty of Hospitality and Tourism students reported greater use of both active and avoidant psychological coping than Faculty of International Studies students did. Furthermore, emotional coping reliably distinguished between males and females as well as between students from the two faculties, so that males and the Faculty of Hospitality and Tourism students reported less use of emotional coping. There is currently insufficient information on gender, faculty, and university year level differences in second language proficiency, self-efficacy, or foreign language anxiety to be able to judge whether the significant differences above are unique to this sample or characteristic of NESB university student cohorts generally. Notwithstanding, they signal the need for universities to know about and anticipate the needs of students from different demographic and academic backgrounds, in order to ensure that appropriate support is targeted effectively and efficiently toward those needs.

In summary, the present research found that depression was the strongest predictor of educational adjustment, followed by motivation to develop occupational talents. Foreign language anxiety, active coping, and English language self-efficacy were also strong predictors of educational adjustment. English language proficiency as measured by TOEIC was not a reliable predictor of educational adjustment. This finding, which is contrary to previous findings, may reflect the bilingual learning, social, and support environment that Thai students studying at a Thai university encounter, despite the requirement that they should study ESL.

For Thai students who are required by Thai universities to learn English, encouragement of a non-judgmental educational environment facilitated by extracurricular activities conducted in English and additional, supplementary, personal study opportunities may assist in increasing students' English self-efficacy and reducing foreign language classroom anxiety. Students need to be reassured that making mistakes is a part of the second language learning process. They may then be less embarrassed, more eager to learn and practise their English, and thus, may adjust better educationally to university life. Establishing and encouraging an English-speaking environment may also help students to become more proficient in English although it must be remembered in the present circumstances that English language proficiency itself was not a reliable predictor of how well first-year Thai students adjust to university study. Classroom, extracurricular, and even formal (e.g., student assembly) rituals that promote and reinforce students' confidence about using and practicing English as a medium of communication and learning have an important role to play in aiding the adjustment process.

Students need assistance to understand and deal with transition to university, especially in their first year. It is essential for both Thai and non-Thai universities to provide psychological support for students who are experiencing symptoms of psychological distress and amotivation. This is particularly the case with students who are experiencing symptoms of depression and/or who do not have a perception of university study as an opportunity to develop their occupational talents as a means of preparing for a career following graduation. Availability and use of psycho-educational and counseling support may assist these students by enhancing occupational aspirations and reducing levels of depression. However, students may be unwilling to seek psychological and academic counseling, if they believe there is a social stigma attached to accessing counseling services. Therefore, alternative ways of assisting students, such as mentoring and career counseling, need to be implemented in order to reduce any perception of stigma and to promote the concept of first-year university as a psychologically supportive environment. Universities could also introduce training in the use of active 
psychological coping, as part of university orientation so that students are aware of the demands of the first-year study, learn to anticipate those demands, and appreciate the support services that are available to them. The challenge for Thai universities in which learning ESL is a compulsory degree component, therefore, is to judiciously apportion financial and human resources to both English language instruction and educational, including psychological, support services, bearing in mind our research findings that the latter support services may be more influential that the former instructional services in influencing how well students adjust to university study. An additional challenge for universities, in which the sole medium of instruction, educational support services, and social life is English, is to broaden the base of bilingual support in order to reduce the influence of English language proficiency as a major factor in adjusting to the first year of study.

Although the students who participated in the research constituted a representative sample (the large majority) of Thai students enrolled in introductory English language programs at a major campus of one Thai university, it is important to understand that the results must be interpreted in this context. Differences between the present findings and the findings of research with overseas NESB students studying in English language universities, which relate to the role of English language proficiency in educational adjustment, suggest that the current findings may not hold for students of non-Thai-speaking backgrounds who enroll in Thai universities. Further research is required in order to understand how Thai universities may best serve and address the needs of their non-Thai students. Second, faculty differences in educational adjustment and its influences were evident. Further research with students drawn from a broader range of faculties and majors may assist universities to develop a thorough understanding of the educational and psychological adjustment needs of their total student bodies. There is also the need to verify the results in a broader range of metropolitan and rural universities in the Thai context. Finally, with a view to developing a more comprehensive understanding of the separate but related roles of second language proficiency, second language classroom anxiety, and second language self-efficacy in adjusting to university in learning settings where the medium of instruction is the second language, further research into psychosocial aspects of second language learning and educational adjustment is required.

\section{References}

Baker, S. R. (2004). Intrinsic, extrinsic, and a motivational orientations: Their role in university adjustment, stress, well-being, and subsequent academic performance. Current Psychology: Developmental, Learning, Personality, Social, 23, 189-202.

Ben-Zur, H. (2009). Coping styles and affect. International Journal of Stress Management, 16, 87-101.

Brislin, R. W. (1970). Back-translation for cross-cultural research. Journal of Cross-Cultural Psychology, 1, 185-216.

Brown, L. (2008). Language and anxiety: An ethnographic study of international postgraduate students. Evaluation \& Research in Education, 21, 75-95.

Cha, E. S., Kim, K. H., \& Erlen, J. A. (2007). Translation of scales in cross-cultural research: Issues and techniques. Journal of Advanced Nursing, 58, 386-395.

Chapman, M. (2006). An over-reliance on discrete item testing in the Japanese business context. Paper presented at The International Conference on English Instruction and Assessment, April 22-23, 2006, National Chung Cheng University, Taiwan.

Cohen, M., Ben-Zur, H., \& Rosenfeld, M. J. (2008). Sense of coherence, coping strategies, and test anxiety as predictors of test performance among college students. International Journal of Stress Management, 15, 289-303.

Cotterall, S. (1999). Key variables in language learning: What do learners believe about them? System, 27, 493-513.

Dowdy, E., diStefano, C., Dever, B. V., \& Chin, J. K. (2011). Screening for emotional and behavioral risk among students with limited English proficiency. School Psychology Quarterly, 26, 14-26. 
Eaele, E. E. (1936). The adjustment problems of college freshmen and contributory factors. Journal of Applied Psychology, 20, 60-76.

Fadlelmula, F. K. (2010). Educational motivation and students' achievement goal orientations. Procedia-Social and Behavioral Sciences, 2, 859-863.

Gan, Y., Hu, Y., \& Zhang, Y. (2010). Proactive and preventive coping in adjustment to college. The Psychological Record, 60, 643-658.

Gardner, R. C., \& Lambert, W. E. (1959). Motivational variables in second-language acquisition. Canadian Journal of Psychology/Revue Canadienne de Psychologie, 13, 266-272.

Gardner, R. C., \& Lysynchuk, L. M. (1990). The role of aptitude, attitudes, motivation, and language use on second-language acquisition and retention. Canadian Journal of Behavioural Science, 22, 254-270.

Garris, R., Ahlers, R., \& Driskell, J. E. (2002). Games, motivation, and learning: A research and practice model. Simulation and Gaming, 33, 441-467.

Henry, J. D., \& Crawford, J. R. (2005). The short-form version of the Depression Anxiety Stress Scales (DASS-21): Construct validity and normative data in a large non-clinical sample. British Journal of Clinical Psychology, 44, 227-239.

Hoffman, J. A. (1984). Psychological separation of late adolescents from their parents. Journal of Counseling Psychology, 31, 170-178.

Horwitz, E. K. (1986). Preliminary evidence for the reliability and validity of a foreign language anxiety scale. TESOL Quarterly, $20,559-562$.

Horwitz, E. K. (2001). Language anxiety and achievement. Annual Review of Applied Linguistics, 21, 112-126.

Horwitz, E. K., Horwitz, M. B., \& Cope, J. (1986). Foreign language classroom anxiety. The Modern Language Journal, 70(2), 125-132.

Hysenbegasi, A., Hass, S. L., \& Rowland, C. R. (2005). The impact of depression on the academic productivity of university students. The Journal of Mental Health Policy and Economics, 8, 145-151.

Khawaja, N. G., \& Dempsey, J. (2007). Psychological distress in international university students: An Australian study. Australian Journal of Guidance \& Counselling, 17, 13-27.

Kim, Y. H., Davidson, G. R., \& Ho, R. (2011). Differences in English language proficiency, self-efficacy, anxiety, coping, and psychological wellbeing between educationally well and less well adjusted Thai students enrolled in first year university English language courses. In Proceedings of The 4th Annual PSU Phuket Conference, November 16-18, 2011, Prince of Songkla University, Phuket, Thailand.

Krause, K. L., Hartley, R., James, R., \& McInnis, C. (2005). The first year experience in Australian universities: Finding from a decade of national studies. Canberra, Australia: Australian Government Department of Education, Science and Training.

Kuh, G. D. (2007). What student engagement data tell us about college readiness. Peer Review, 9, 4-8.

Lalonde, R. N., \& Gardner, R. C. (1984). Investigating a causal model of second language acquisition: Where does personality fit? Canadian Journal of Behavioural Science, 16, 224-237.

Lapsley, D. K., Rice, K. G., \& Shadid, G. E. (1989). Psychological separation and adjustment to college. Journal of Counseling Psychology, 36, 286-294.

Liu, L. L., Benner, A. D., Lau, A. S., \& Kim, S. Y. (2009). Mother-adolescent language proficiency and adolescent academic and emotional adjustment among Chinese American families. Journal of Youth and Adolescence, 38, 572-586.

Lovibond, S. H., \& Lovibond, P. F. (1995). Manual for the depressionanxiety stress scales (2nd ed.). Sydney, Australia: Psychology Foundationof Australia.

McInnis, C. (2001). Researching the first year experience: Where to from here? Higher Education Research \& Development, 20 , 105-114.

McInnis, C., \& James, R. (1995). First year on campus: Diversity in the initial experience of Australian undergraduates. Canberra, Australia: AGPS.

Misra, R., \& Castillo, L. G. (2004). Academic stress among college students: Comparison of American and international students. International Journal of Stress Management, 11, 132-148.

Misra, R., Crist, M., \& Burant, C. J. (2003). Relationships among life stress, social support, academic stressors, and reactions to stressors of international students in the United States. International Journal of Stress Management, 10, 137-157.

National Centre in HIV Epidemiology and Clinical Research. (2007). DASS21 (Thai version). Sydney, Australia. Retrieved May 1, 2011, from http://www2.psy.unsw.edu.au/groups/dass/Thai/NCHECR_Thai.htm 
Olivas, M., \& Li, C. S. (2006). Understanding stressors of international students in higher education: What college counselors and personnel need to know. Journal of Instructional Psychology, 33, 217-222.

Park, C. L., \& Adler, N. E. (2003). Coping style as a predictor of health and well-being across the first year of medical school. Health Psychology, 22, 627-631.

Randall, M., Naka, K., Yamamoto, K., Nakamoto, H., Arakaki, H., \& Ogura, C. (1998). Assessment of psychological stressors and maladjustment among foreign students of the University of the Ryukyus. Psychiatry and Clinical Neurosciences, 52, 289-298.

Rueda, R., \& Chen, C. B. (2005). Assessing motivational factors in foreign language learning: Cultural variation in key constructs. Educational Assessment, 10, 209-229.

Struthers, C. W., Perry, R. P., \& Menec, V. H. (2000). An examination of the relationship among academic stress, coping, motivation, and performance in college. Research in Higher Education, 41, 581-592.

Swagler, M. A., \& Ellis, M. V. (2003). Crossing the distance: Adjustment of Taiwanese graduate students in the United States. Journal of Counseling Psychology, 50, 420-437.

Tremblay, P. F., \& Gardner, R. C. (1995). Expanding the motivation construct in language learning. The Modern Language Journal, 79, 505-518.

Welbourne, J. L., Eggerth, D., Hartley, T. A., Andrew, M. E., \& Sanchez, F. (2007). Coping strategies in the workplace: Relationships with attributional style and job satisfaction. Journal of Vocational Behavior, 70, 312-325.

Wilson, K. M. (2001). Overestimation of LPI ratings for native-Korean speakers in the TOEIC testing context: Search for explanation. Princeton, N. J.: Educational Testing Service.

Wiriyachitra, A. (2002). English language teaching and learning in Thailand in this decade. Thai TESOL Focus, 15(1), 4-9.

Woodford, P. E. (1982). The test of English for international communication. In C. Brumfit (Ed.), English for international communication (pp. 1-16). New York, N. Y.: Pergamon Press.

Woodrow, L. (2006). Anxiety and speaking English as a second language. RELC Journal, 37, 308-328.

Zajacova, A., Lynch, S. M., \& Espenshade, T. J. (2005). Self-efficacy, stress and academic success in college. Research in Higher Education, 46, 677-706.

Zimmerman, B. J. (2000). Self-efficacy: An essential motive to learn. Contemporary Educational Psychology, 25, 82-91. 